Patriv B, Ahmed YA. (2013). Communication skills training in the medical curriculum. Journal of Education and Learning. Vol.7 (3) pp. 129-134.

\title{
Communication Skills Training in the Medical Curriculum
}

\author{
Branet Partric ${ }^{*}$ \\ Cross Modal Research Center. \\ Oxford University \\ Yasar Albushra Ahmed ${ }^{* *}$ \\ Princess Noorah oncology Center \\ King Abdulaziz Medical City
}

\begin{abstract}
Communication is an essential skill in the armory of any worker in the health field. It is an integral part of the skills required, not only in medical doctors, but in all health workers. Communication is more than history taking; it includes all methods of interaction with patients, patient's relatives, members of the health care team, and the public. Many studies stressed that the main complaints of patients are related to communication problems and not to clinical competency. This has contributed to an increase in the number of law suits, non-adherence to medical regimens, and the tendency of patients to keep changing physicians and hospitals. Also, it has been shown that health outcome is positively affected by proper communication. This includes patient's satisfaction and cooperation, decrease in treatment duration, decrease in painkillers requirements, and decrease in hospital stay. Also, it has been shown that communication skills can be taught and important changes in physician's behavior and in their communication skills have been demonstrated after courses of communication skills. Thus, many medical colleges in the world are including communication skills courses in their undergraduate and graduate curricula.
\end{abstract}

Keywords: communication, skills, curriculum, Calgary-Cambridge

\footnotetext{
*Branet Partric , Cross Modal Research Center. Department of Educational Psychology. Oxford University E-mail: medicine2u@yahoo.co.uk

${ }^{* *}$ Yasar Albushra Ahmed. Princess Noorah oncology Center King Abdulaziz Medical City National Guard Health Affairs P.O BOX 9515 Jeddah 21423

Phone +966592908110

Fax: +966-2-6247242

Email:drhammor@yahoo.co.uk
} 


\section{Introduction}

A multidisciplinary approach is recommended in the management of most medical ailments. Communication between doctors, paramedical staff, and importantly, between the medical team and the patient and relatives has been discussed in the medical literature. Patients have different psycho-social needs and tailoring the communication to the patients' requirements is highly valued. ${ }^{[1]},{ }^{[2]}$ Communicating the key points during each step of the patient's journey is now considered to be an essential criterion for good medical practice and improves the job satisfaction of doctors. ${ }^{[3]}$ The benefits of communicating appropriately have been investigated in the setting of clinical oncology and studies have reported improved treatment adherence and better psychological performance by our patients. ${ }^{[4]}$ Studies ${ }^{[5]}$ have also looked at cultural and gender differences in the motivation of blood donors, making it important to develop individualized communication strategies. Communication skills are not routinely taught in many medical undergraduate or postgraduate courses in this region, and there is a feeling that in a busy outpatient department, such skills may not be optimally applied

Communication is an essential skill in the armory of any worker in the health field. It is an integral part of the skills required, not only in medical doctors, but in all health workers. ${ }^{[7],}{ }^{[8]}$ Communication is more than history taking and eliciting signs and proper communication requires adequate knowledge, suitable skills, and the right attitude.

The importance of formal teaching of communication skills has been recognized. Many medical colleges in the world and an increasing number of nursing schools have included communication skills courses in their undergraduate as well as postgraduate curriculum. ${ }^{[8],[9]}$

Education is all about communication - not only of hard facts but also of thoughts and ideas and proposals on which to base discussion and debate. However, there is one thing lacking in almost all education systems around the world and that is, teaching students how to communicate their thoughts to others. This results in producing professionals who may have good domain knowledge but are unprepared for what the world needs. This is particularly true in the field of medical education

\section{Communication skills at glance What do we mean by communication skills?}

History taking is an essential component of communication by which information can be retrieved from patients. But, communication with patients is more than just history taking; it includes all methods of interaction with patients. This includes the ability to:

- Take a complete history of the disease including past, social, and family history.

- Discuss diagnosis, treatment options, prognosis, and possible complications.

- Understand the physical, psychological, social, and religious concerns and needs of patients.

- Convey trust, comfort, and relieve mental blocks.

- Deliver bad and distressing news.

- Deal with ethical and controversial issues.

- Deal with difficult or distressed patients and their relatives.

- Communicate with patient's relatives, colleagues, health workers, administrators, and decision makers.

\section{Justification}

Many studies reiterate that effective communication and relationship-building are important in the delivery of high-quality health care. ${ }^{[9],}{ }^{[10],}{ }^{[11]}$ Stewart, ${ }^{[11]}$ in a review of several studies about effective physician-patient communication and health outcome concluded that health outcome is positively affected by probing the thoughts, feelings, and expectations of patients, encouraging them to ask questions, and allowing patients to share in the decision making. These effects are documented in the reduction of anxiety, psychological distress, pain relief, symptom resolution, mood improvement, and reduction of high blood pressure. Improved communication has also been shown to increase satisfaction of patients, cooperation of patients, decrease in the duration of treatment, decrease in the intake of painkillers, and decrease in hospital stay. ${ }^{[12],[13],[14],[15]}$

The Toronto Consensus statement stressed that the main complaints of patients are related to communication problems and not to clinical competency. ${ }^{[16]}$ Furthermore, substantial communication deficiencies were noticed in physicians including residents and trainees. ${ }^{[16]}$ Similarly, the main remark made by patients in the primary health care centers in Riyadh. Saudia Arabia, was that physicians were not listening enough to their complaints. ${ }^{[17]}$ The magnitude of the problem of poor communication is demonstrated by the increase in patient's complaint, the increasing number of law suits against doctors and hospitals, the tendency of patients to keep changing physicians and hospitals, and non-adherence to 
medical regimen. ${ }^{[16],[18],[17]}$ The association between specific communication patterns and law suits was found in a study done on primary care physicians. ${ }^{[8]}$ Many hospital administrators, heads of departments and other health care leaders will testify to the fact that a great deal of their daily energy is spent in issues related to patient's complaints. The majority of these are related to poor communication and most of them could have been solved by a proper communication. Another important observation is the tendency of the same person to have one complaint against him after another. Many of these are related to a fault in communication rather than a mistake in management

\section{How to learn and teach communication skills}

There is some evidence to suggest that short courses of one day or less are not sufficient. ${ }^{[7]}$ Also, learning communication skills during clinical rotations is probably more beneficial than in the pre-clinical period. ${ }^{[7]}$ Learning by doing has been shown to be more effective than by the traditional lecture approach and feedback is valuable in the learning process. ${ }^{[21], ~[22], ~[23] ~ T h e r e f o r e, ~}$ experiential methods should be used rather than the traditional instructional methods. Video tape or audio tape recordings can be used for demonstrations. Consultations can be done using real patients, simulated patients, or even role plays. ${ }^{[24]}$ The most commonly used teaching methods in the British medical colleges are tutorials, video feedback, role playing, and lectures. ${ }^{[25], ~[26], ~}{ }^{[27]}$ Some communication skills teaching models have been well described in the literature, with instructions on how to teach the model. ${ }^{[24]}$ One can choose among these according to the objectives of the course. ${ }^{[24]}$

\section{Setting up a Communication Skills Training Program}

Various models can be used which could enable adequate training to sharpen the skills required for communication. Based on a recent recommendation, ${ }^{[28]}$ mandatory communication skills training courses should be made available in the undergraduate and postgraduate medical training. Whilst longer courses ${ }^{[29], ~[30]}$ within the undergraduate curriculum have been proven to be of benefit, not all courses have such modules. Simple areas like how to listen effectively, when to pause, how to allow patients to vent their frustration and how to encounter barriers of communication (like language and cultural issues) can be covered in a short workshop over a few days. A recent meta-analysis of 13 controlled studies of communication skills teaching has ${ }^{[31]}$ shown a moderate improvement in the communication skills following attendance of such courses. Similar results have been reported by a prior Cochrane review group. ${ }^{[32]}$ Following basic course, a further consolidation course was found to improve the skills of the participant further. ${ }^{[33]}$ Due to the likeliness of fewer benefits from courses lasting for less than 3 days, the authors recommended that a training course for communication skills should be at least 3 days or more in duration to enable all topics to be covered in sufficient depth. Role plays with experienced facilitators who could guide the learners have been found to help in adequate development of the necessary skills, thereby implying that the skills of the trainers need to be adequately assessed. ${ }^{[34]}$ Small group course discussions are preferred to ensure optimal participation by all the group members. ${ }^{[33]}$ A set of objectives must be agreed upon prior to starting the course. Similarly, specific goals on how to handle emotionally difficult clinical scenarios, build relationship and confidence, and discuss complex information with the patient must be covered in these courses. ${ }^{[33]}$ Various methods of teaching have been used, including the use of videos, role plays, and didactic lectures. A validated outcome measurement tool should be used to assess the benefits of such courses.

\section{Patient-Centered Model}

Developed and refined over the past 30 years, the patient-centered model integrates the conventional understanding of disease (medical model) with each patient's unique experience of illness. The traditional notion of the professional being in charge and the patient being passive does not hold in this model. "To be patient-centred, the practitioner must be able to empower the patient, to share the power in the relationship."

The patient-centered model consists of six interconnecting components. The first three components address the process between patient and doctor. The second three components shift the focus to the context of the patient-physician interaction. Ideally, the physician moves among these six components, in response to cues received from the patient. The six components of the patient centred model are briefly described below ${ }^{(35)}$

1-Exploring both the disease and the illness experience:

Effective patient care requires attending as much to patients' personal experiences of illness as to their diseases. The patient-centred method focuses on disease and on four principal dimensions of patients' illness experiences: a) their ideas about what is wrong with them; b) their feelings, especially 
fears about being ill; c) the impact of their problems on functioning; and d) their expectations about what should be done.

2-Understanding the whole person:

Over time, physicians come to know the context of the patient's life, including family, work, beliefs and life crises. Understanding the whole person can enhance the physician's interaction with the patient - especially when the symptoms do not point to a specific illness. It can also help to deepen the doctor's knowledge of the human condition, especially the nature of suffering.

3-Finding common ground regarding management

Patients and physicians often have widely divergent views about the nature of the problems and priorities; the goals of treatment; and the roles of the doctor and the patient. Finding common ground involves the physician in incorporating patients' ideas, feelings, expectations and function into treatment planning.

4-Incorporating prevention and health promotion

This task requires that continuing and comprehensive care be the underlying philosophy of the physician's practice. Within a supportive process, physicians and patients together monitor areas in patients' lives that need strengthening in the interests of long-term emotional and physical health.

5-Enhancing the patient-doctor relationship

At every visit, physicians strive to build an effective long-term relationship with each patient as a foundation for their work together. They can then use this relationship to help mobilize the strengths of the patient for healing.

6-Being realistic

Doctors must be able to manage their time effectively, developing skills of priority-setting, resource allocation and teamwork. They must also respect their own limits of emotional energy and not expect too much of themselves ${ }^{.(35)(36)}$

\section{Calgary-Cambridge Observation Guide}

The Calgary-Cambridge Observation Guide uses a simple five-point plan to structure individual communication skills. Based on a sequence of basic tasks that physicians and patients routinely attempt to accomplish in everyday clinical practice, the plan provides a logical organizational schema for both patient-physician interactions and communication skill education. ${ }^{(37 .)}$ As indicated, each of these five tasks includes an expanded framework of skill sets which provide further detail about the goals to be achieved.

1 - Initiating the session

- establishing initial rapport

- identifying the reason(s) for the consultation

2- Gathering information

- exploration of problems

- understanding the patient's perspective

- providing structure to the consultation

3- Building the relationship

- developing rapport

- involving the patient

4- Explanation and planning

- providing the correct amount and type of information

- aiding accurate recall and understanding

- achieving a shared understanding: incorporating the patient's perspective

- planning: shared decision making

- options in explanation and planning

— if discussing opinion and significance of problem

- if negotiating mutual plan of action

— if discussing investigations and procedures

6- Closing the session ${ }^{(37)(38)}$

\section{Conclusions}

The use of effective and formal communication skills training is required for medical professionals. Communication skills are an important component of the learning objectives of medical doctors and health care workers in general. The availability of such courses in our country is fragmented and a structured program needs to be in place to ensure that our doctors are supported adequately and patients get the best standards of care. The lack of which can adversely affect the health outcome of 
patients. Similarly, it can be a source of conflict, stress, and waste of resources. Many medical colleges in the world are including communication skills courses in their undergraduate and graduate curricula. We should do the same in our medical colleges

\section{Acknowledgement}

All the authors would extend their heartfelt thanks to Dr. Elisabeth Anne MacDonald for her immense and selfless contribution toward manuscript preparation and final approval of the text.

\section{References}

1. Parker PA, Baile WF, de Moor C, Lenzi R, Kudelka AP, Cohen L. Breaking bad news about cancer: patients' preferences for communication. J Clin Oncol, 2001; 19: 2049-56.

2. Hack TF, Degner LF, Parker PA. The communication goals and needs of cancer patients: a review. Psychooncology, 2005; 14: 831-45.

3. Maguire P, Pitceathly C. Key communication skills and how to acquire them. BMJ, 2002; 325 : $687-700$

4. Arora NK. Interacting with cancer patients: the significance of physicians' communication behavior. Soc Sci Med, 2003; 57: 791-806.

5. Marco Bani, Barbara Giussani. Gender differences in giving blood: a review of the literature. Blood Transfus, 2010; 8: 278-87.

6. General Medical Council, UK, Education Committee. Tomorrow's Doctors. London, General Medical Council. Available from: http:/www.gmcuk.org/education/undergraduate/undergarduate_policy/tomorrows_doctors.asp.

7. Aspegren K. Teaching and learning communication skills in medicine: A review with quality grading of articles. Med Teach, 1999; 21: 563-70.

8. Association of American Medical Colleges. Contemporary Issues in Medicine: Communication in Medicine. Medical Schools Objectives Project, Report III, Washington, DC: Association of American Medical Colleges; 1999.

9. Roter DL, Hall JA, Katz NR. Relations between physician's behaviors and analogue patient's satisfactions, recall, and impressions. Med Care, 1987; 25: 437-51.

10. Bertakis KD, Roter D, Puntnam SM. The relationship of physician medical interview style to patient satisfaction. J Fam Pract, 1991; 32: 175-81.

11. Stewart MA. Effective physician-patient communication and health outcome: A review. Can Med Assoc J, 1995; 152: 1423-33.

12. Egbert LD, Batitt GE, Welch CE. Reduction of postoperative pain by encouragement and instruction of patients. New Engl J Med, 1964; 270: 825-7.

13. Eisenthal S, Lazare A. Evaluation of the initial interview in a walk-in clinic. J Nerv Ment Dis, 1976; 162: 169-76.

14. Mumford E, Schlesinger HJ, Glass GV. The effect of psychological intervention on recovery from surgery and heart attacks: An analysis of the literature. Am J Public Health, 1982; 72: 141-51.

15. Van Dalen J, Bartholomeus P, Kerkhofs E, Lulofs R, van Thiel J, Rethans JJ, et al. Teaching and assessing communication skills in Maastricht: The first twenty years. Med Teach, 2001; 23: 24551.

16. Simpson M, Buckman R, Stewart M, Maguir, P, Lipkin M, Novack D, et al. Doctor-patient communication: The Toronto consensus statement. Br Med J 1991;303:1385-7

17. Saeed AA, Mohammed BA, Magzoub ME, Al-Doghaither AH. Satisfaction and correlates of patients' satisfaction with physicians' services in primary health care centers. Saudi Med J, 2001; 22: $262-7$.

18. Vincent C, Young M, Phillips A. Why do people sue doctors? A study of patients and relatives taking legal action. Lancet, 1994; 343: 1609-13.

Patriv B, Ahmed YA. (2013). Journal of Education and Learning. Vol.7 (3) pp. 129-134. 
19. Meryn S. Improving communication skills: To carry coals to newcastle? Med Teach, 1998; 20: 331-6.

20. Levinson W, Roter DL, Mullooly JP, Dull VT, Frankel RM. Physician-patient communication. The relationship with malpractice claims among primary care physicians and surgeons. JAMA Am Med Assoc, 1997; 277: 553-9.

21. Maguire P, Clarke D, Jolly B. An experimental comparison of three courses in history-taking skills for medical students. Med Educ, 1977; 11: 175-82.

22. Maguire P, Roe P, Goldberg D, Jones S, Hyde C, O'Dowd T. The value of feedback in teaching interview skills to medical students. Psychol Med, 1978; 8: 695-704.

23. Maguire P, Fairbairn S, Fletche C. Consultation skills of young doctors: 1 - benefits of feedback training in interviewing as students persist. Br Med J, 1986; 292: 1573-6.

24. Snadden D, Ker JS. Communication skills. A practical guide for medical teachers. London: Churchill Livingstone; 2001.

25. Whitehouse CR. The teaching of communication skills in United Kingdom Medical Schools. Med Educ, 1991; 25: 311-8.

26. Consensus Statement from the Workshop on the Teaching and Assessment of Communication Skills in Canadian Medical Schools. Can Med Assoc J, 1992; 147: 1149-52.

27. Frederikson L, Bull P. An Appraisal of the current status of communication skills training in British Medical Schools. Soc Sci Med, 1992; 34: 515-22.

28. Stiefel F, Barth J, Bensing J, Fallowfield L, Jost L, Razavi D, et al. Communication skills training in oncology: a position paper based on a consensus meeting among European experts in 2009. Ann Oncol, 2010; 21: 204-7

29. Marion GS, Hildebrandt CA, Davis SW, Marin AJ, Crandall SJ. Working effectively with interpreters: amodel curriculum for physician assistant students. Med Teach, 2008; 30: 612-7.

30. McEvoy M, Santos MT, Marzan M, Green EH, Milan FB. Teaching medical students how to use interpreters: A three year experience. Med Educ Online, 2009; 14: 12.

31. Barth J, Lannen P. Efficacy of communication skills training courses in oncology: a systematic review and meta-analysis. Ann Oncol, 2010.

32. Moore PM, Wilkinson SS, Rivera Mercado S. Communication skills training for health care professionals working with cancer patients, their families and/or carers. Cochrane Database Syst Rev, 2001; 2: CD003751.

33. Liénard A, Merckaert I, Libert Y, Bragard I, Delvaux N, Etienne AM, et al. Transfer of communication skills to the workplace during clinical rounds: impact of a program for residents. PLoS One, 2010; 5: e12426

34. Bylund CL, Brown RF, Lubrano di Ciccone B, Diamond C, Eddington J, Kissane DW. Assessing facilitator competence in a comprehensive communication skills training programme. Med Educ, 2009; 43: 342-9.

35. Knut A, Peter L.Which basic communication skills in medicine are learnt spontaneously and which need to be taught and trained? Medical Teacher, 2005; 27(6): 539-3

36. Talking Tools II- Putting Communication Skills to Work. A Three-Hour Interactive Course for Practicing Physicians- Resource Booklet. Available at http://publications.gc.ca/collections/Collection/H39-509-2001-2E.pdf

37. Kurtz, S.M., and J.D. Silverman. "The Calgary-Cambridge observation guides: an aid to defining the curriculum and organising the teaching in communication training programmes." Medical Education, 1996; 30: 83-89.

38. Kurtz, S., J. Silverman and J. Draper. Teaching and Learning Communication Skills in Medicine. Oxford, UK: Radcliffe Medical Press, 1998. 